\title{
A MANUAL METHOD TO OBTAIN PLATELET RICH PLASMA
}

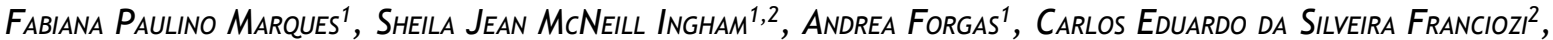 \\ Pedro Henrique Sasaki ${ }^{1,2}$, Rene Jorge Abdalla ${ }^{1,2}$
}

\section{ABSTRACT}

Objective: This study is to report a manual method to obtain platelet rich plasma (PRP). Methods: For this study $61 \mathrm{ml}$ of peripheral blood was obtained and submitted to centrifugation at $541 \mathrm{~g}$ for $5 \mathrm{~min}$. The centrifugation separates the blood into three components: red blood cells, buffy coat and platelet rich plasma. Blood and platelet rich plasma samples were sent to the Hospital's Laboratory and platelets and leukocytes were measured. Results: A sample of 637 blood donors was evaluated. The platelet yield efficiency was $86.77 \%$ and the increase in platelet concentration factor was 2.89 times. The increase in leukocyte concentration factor was 1.97 times. Conclusion: The method described here produces leukocyte-rich and platelet-rich plasma with a high platelet and leukocyte increased factor. Level of Evidence IV, Controlled Laboratory Study.

Keywords: Platelet-rich plasma. Blood platelets. Methods.

Citation: Marques FP, Ingham SJM, Forgas A, Franciozi CES, Sasaki PH, Abdalla RJ. A manual method to obtain platelet rich plasma. Acta Ortop Bras. [online]. 2014;22(2):75-7. Available from URL: http://www.scielo.br/aob.

\section{INTRODUCTION}

Platelet-rich plasma (PRP) was first described by Whitman et al. ${ }^{1}$ in 1997 as a derivative of fibrin glue made by Matras, ${ }^{2}$ and today its use has been widely documented in the medical and dentistry literature. ${ }^{3-5}$ Dental surgeries, plastic surgeries, as well as orthopedics, have shown good results with the use of PRP to obtain better healing. ${ }^{3-12}$ Although most reported positive results, there is no conclusive evidence of the effect of PRP on tissue healing ${ }^{13}$ and one of the reasons could be the lack of knowledge of the basic characteristics of PRP, as the number of platelets required, and the need for activation of these platelets. ${ }^{3}$

PRP can be defined as a fraction of a volume of plasma that has a higher concentration of platelets than in peripheral blood. ${ }^{14,15}$ Platelet concentration and amount of growth factors in the PRP depend on the technique used, ${ }^{16}$ but on average, PRP has 3-5 times more growth factors than peripheral blood. ${ }^{17}$ Today there are several techniques to obtain PRP and this has led to confusion regarding the classification, ${ }^{17-19}$ the time and the centrifugation speed, which are extremely variable. ${ }^{18}$

The use of PRP for tissue regeneration has grown, but it still needs further research and clarification regarding methods of its obtention ${ }^{20}$. The aim of this study is to demonstrate a new manual method of obtaining PRP.

\section{MATERIALS AND METHODS}

This study was approved by the Ethics Committee and was conducted in accordance with the ethical standards established by the Helsinki Declaration of 1964. All subjects who underwent knee surgery at our institution who received PRP were included in this study. All subjects gave informed consent before inclusion in the study. Data were collected from 2008 to 2010.

For this study $61 \mathrm{ml}$ of peripheral blood was collected from each patient. One milliliter was used to count the number of platelets and leukocytes in the peripheral blood and $60 \mathrm{ml}$ were used to obtain PRP. Five milliliters of the anticoagulant sodium citrate were used and centrifugation at $541 \mathrm{~g}$ for 5 minutes (Centribio 80-2B centrifuge Centribio, São Paulo, SP, Brazil) to obtain $18 \mathrm{ml}$ of PRP and $14 \mathrm{ml}$ of poor platelet plasma. (Figures 1 and 2) Centrifugation separates blood into three components: red blood cells, buffy coat and PRP. PRP and buffy coat are carefully collected to prevent any contamination with red blood cells.

Samples of whole blood and PRP were sent to the hospital laboratory and platelets and leukocytes were quantified with a Sysmex - XT1800i hematology analyzer (Sysmex America, Inc., Mundelein, Illinois). preparation described in this paper. The other authors do not have any conflict of interest.

\footnotetext{
1. Knee Institute, Hospital do Coração (HCor), São Paulo, SP, Brazil.

2. Department of Orthopedics and Traumatology, Escola Paulista de Medicina, Universidade Federal de São Paulo, São Paulo, SP, Brazil.
}

Work developed at Hospital do Coração (HCor), São Paulo, SP, Brazil.

Correspondence: Rene Jorge Abdalla, Rua Abílio Soares, 227, cj. 31. 04005-000, São Paulo, SP. Brazil. rene.abdalla@globo.com 


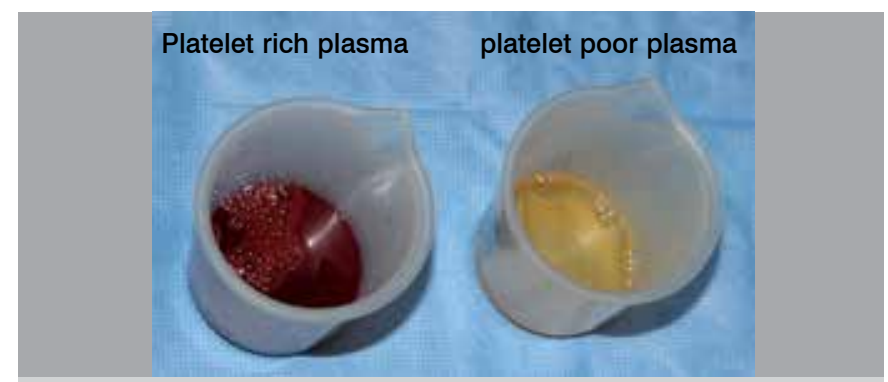

Figure 1. Platelet poor plasma (right) and platelet rich plasma (left).

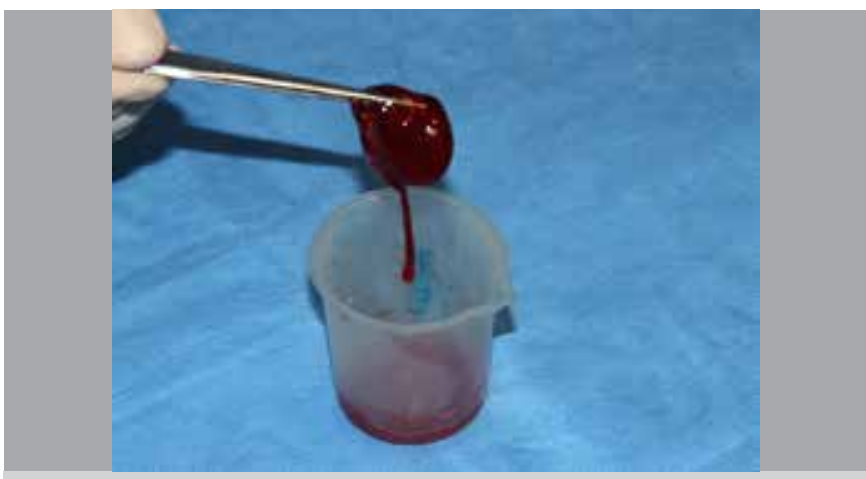

Figure 2. Platelet rich plasma clot activated with autologous thrombin and $10 \%$ calcium gluconate.

\section{STATISTICAL ANALYSIS}

Statistics data was calculated using a statistical software SPSS version 17.0 (SPSS Inc., Chicago, IL, USA). The Wilcoxon test was used to compare values pre-and post-centrifugation. The Mann-Whitney and Kruskal-Wallis tests were used to compare the difference between groups. Dunn's multiple comparison was used as post hoc test. Data are presented as mean \pm standard deviation. Statistical significance was set at 0.05 .

\section{RESULTS}

A sample of 637 subjects was evaluated. Of these, 637 had the number of platelets in peripheral blood quantified, and 445 had the number of leukocytes quantified in peripheral blood and in PRP. The mean age was $45.78 \pm 15.11$ years old and $75 \%$ were male.

The mean platelet count and leukocytes in peripheral blood was $220.377 \pm 51.484 / \mathrm{mm}^{3}$ e $7.149 \pm 4.777 / \mathrm{mm}^{3}$, respectively, while the number of platelets and leukocytes in PRP was $637.388 \pm$ $189.962 / \mathrm{mm}^{3}$ and $14.056 \pm 11.820 / \mathrm{mm}^{3}$ ( $p<.001$ for both).

The efficiency of platelet capture ${ }^{21}$ (PRP volume $x$ [platelets PRP] / (blood volume $x$ [blood platelets]) was $86.77 \%$ and the increase in the concentration of platelet factor was 2.89 times. The increase in the leukocyte concentration factor was 1.97 times.

In males, the mean platelet count in whole blood was 214,184 $\pm 49.732 / \mathrm{mm}^{3}$ and in PRP it was 626,718 $\pm 191.917 / \mathrm{mm}$ $(p<0.001)$ whereas in females these values were, respectively, $238.994 \pm 52.327 / \mathrm{mm}^{3}$ and $669.465 \pm 180.778 / \mathrm{mm}^{3}$ $(p<0,001)$. The difference between genders was statistically significant for counts in whole blood $(p<0.001)$ and for PRP count $(p=0.005)$.
Table 1 shows the distribution of platelets and leukocytes, divided by different age groups. Post- hoc analysis using Dunn's multiple comparison showed differences in the following groups:

a) Platelets in whole blood: $20-29$ vs. $50-59(p=0,022), 20-29$ vs. $>=70(p=0,026), 40-49$ vs. $50-59(p=0,007), 40-49$ vs. $60-69$ ( $p=0,027)$ e 40-49 vs. $>=70(p=0,017)$;

b) Leucocytes in whole blood: 20-29 vs. 50-59 ( $p=0,03), 30-39$ vs. $50-59$ ( $p<0,001), 30-39$ vs. 60-69 ( $p=0,043), 30-39$ vs. $>=70(p=0,017)$ e 40-49 vs. $50-59(p=0,003)$;

c) Leucocytes in PRP: $20-29$ vs. 50-59 ( $p<0,001), 30-39$ vs. 50-59 ( $p=0,015)$ e 40-49 vs. $50-59(p<0,001)$.

Table 1. Distribution of platelets and leukocytes in whole blood and in PRP according to donor's age.

\begin{tabular}{|c|c|c|c|c|c|c|}
\hline Variable & $\begin{array}{c}\text { Age } \\
\text { (years old) }\end{array}$ & Median & Minimum & Maximum & $\mathbf{N}$ & $\mathrm{p}$ \\
\hline \multirow{7}{*}{$\begin{array}{c}\text { Platelets in } \\
\text { peripheral blood } \\
\text { (platelets } / \mathrm{mm} \text { ) }\end{array}$} & $<20$ & 224.000 & 129.000 & 283.000 & 20 & \multirow{7}{*}{0,032} \\
\hline & $20-29$ & 226.000 & 125.000 & 363.000 & 83 & \\
\hline & $30-39$ & 217.500 & 139.000 & 335.000 & 122 & \\
\hline & $40-49$ & 226.500 & 112.000 & 412.000 & 148 & \\
\hline & $50-59$ & 210.500 & 107.000 & 364.000 & 136 & \\
\hline & $60-69$ & 208.500 & 127.000 & 393.000 & 84 & \\
\hline & $>=70$ & 202.000 & 101.000 & 346.000 & 39 & \\
\hline \multirow{7}{*}{$\begin{array}{r}\text { Platelets in PRP } \\
\text { (platelets/mm3) }\end{array}$} & $<20$ & 597.500 & 429.000 & 835.000 & 20 & \multirow{7}{*}{0,199} \\
\hline & $20-29$ & 627.000 & 216.000 & 1.178 .000 & 83 & \\
\hline & $30-39$ & 604.500 & 248.000 & 1.156 .000 & 122 & \\
\hline & $40-49$ & 636.000 & 304.000 & 1.615 .000 & 148 & \\
\hline & $50-59$ & 621.500 & 203.000 & 1.229 .000 & 136 & \\
\hline & $60-69$ & 580.500 & 301.000 & 1.686 .000 & 84 & \\
\hline & $>=70$ & 644.000 & 273.000 & 1.090 .000 & 39 & \\
\hline \multirow{7}{*}{$\begin{array}{l}\text { Leukocytes in } \\
\text { peripheral blood } \\
\text { (leukocytes } / \mathrm{m} 3 \text { ) }\end{array}$} & $<20$ & 6.555 & 4.610 & 9.000 & 12 & \multirow{7}{*}{0,001} \\
\hline & $20-29$ & 6.810 & 4.090 & 15.280 & 57 & \\
\hline & $30-39$ & 7.100 & 4.290 & 15.960 & 87 & \\
\hline & $40-49$ & 6.880 & 3.700 & 79.990 & 114 & \\
\hline & $50-59$ & 6.230 & 2.660 & 9.360 & 95 & \\
\hline & $60-69$ & 6.500 & 4.200 & 14.860 & 57 & \\
\hline & $>=70$ & 6.150 & 3.700 & 66.600 & 28 & \\
\hline \multirow{7}{*}{$\begin{array}{c}\text { Leukocytes } \\
\text { in PRP } \\
\text { (leukocytes/m3) }\end{array}$} & $<20$ & 12.010 & 9.800 & 17.100 & 12 & \multirow{7}{*}{0,002} \\
\hline & $20-29$ & 14.100 & 3.960 & 36.040 & 63 & \\
\hline & $30-39$ & 13.010 & 3.250 & 39.860 & 95 & \\
\hline & $40-49$ & 13.700 & 3.830 & 209.020 & 118 & \\
\hline & $50-59$ & 10.830 & 4.110 & 28.500 & 102 & \\
\hline & $60-69$ & 12.550 & 4.440 & 32.200 & 66 & \\
\hline & $>=70$ & 11.200 & 5.500 & 140.700 & 28 & \\
\hline
\end{tabular}

\section{DISCUSSION}

This study demonstrates the variability in the number of platelets and leukocytes in peripheral blood and PRP in a large population. We also show that the method described herein shows an increased concentration factor of platelets and leukocytes, and that there is high platelet collection efficiency. We also demonstrated significant difference in platelet count when comparing different ages and gender, since females showed a significantly higher amount than men, and younger people showed higher platelets and leukocytes count.

The use of growth factors as a stimulus for tissue healing has been studied in several areas of orthopedic and dentistry surgery. ${ }^{3-5,22}$ In Orthopedics, it has been successfully used in bone soft tissue healing procedures, in the reconstruction of the anterior cruciate ligament rupture, in Achilles tendon rupture in athletes, and in surgical scar after total knee arthroplasty. ${ }^{3}$ 
(Figure 3) Nevertheless, we have no conclusive evidence on the effect of PRP on the results obtained, ${ }^{3}$ and we do not know yet the best method for PRP application. ${ }^{6}$

A previous study from Castillo et al. ${ }^{21}$ compared three automated methods to obtain PRP. The highest platelet capture efficiency was obtained with Cascade MTF, and it was of $67.6 \%$, a value lower than our study's (86.77\%). This may be due to the large volume of the obtained PRP (18 mL). Moreover, we had a high incremental factor, showing that this manual method may be used to obtain PRP. Obtaining PRP by automated methods is expensive, ${ }^{23}$ and can be prohibitive in developing countries, like ours. The use of a manual centrifuge, available

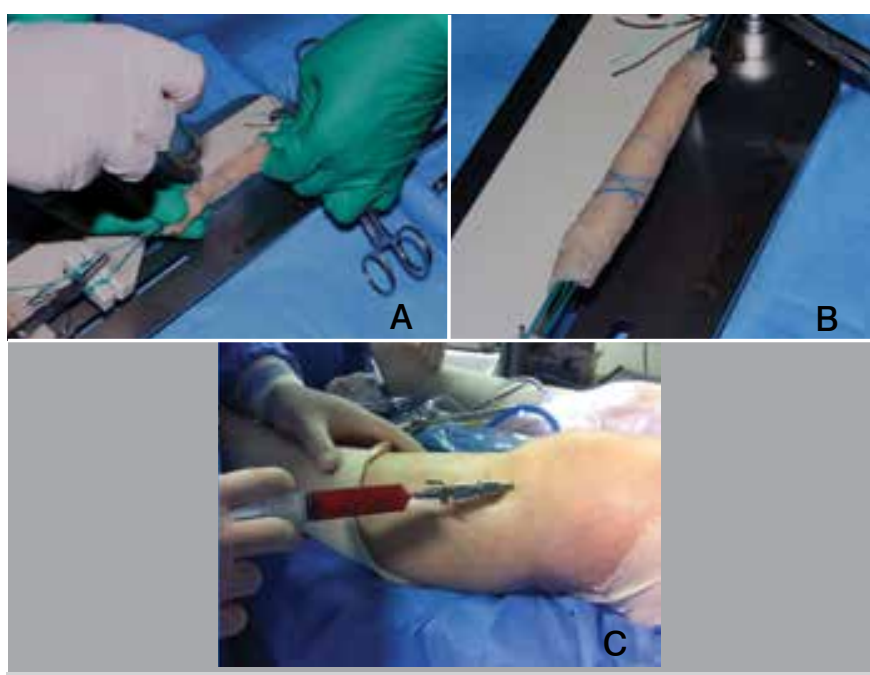

Figure 3. Examples of clinical application of PRP: A) Placement of PRP in autograft to be used for reconstruction of the anterior cruciate ligament; B) Soaked autograft wrapped in gauze soaked with PRP. C) Application of PRP after knee arthroscopy. in most hospitals and surgical centers, can make this method more available and ready to use. Thus, PRP can become a cheaper source of growth factors (PDGF, TGF- $\beta$, VEGF, IGF-1, etc.) and can stimulate the tissue healing. ${ }^{6,7}$ Castillo et al. ${ }^{21}$ also measured the amount of white blood cells and found no difference between whole blood and PRP. This result is different from ours, since we found significant differences $(p<0.001)$ for leucocytes. This may be a result of the manual method used in this study, where the buffy coat was intentionally included in the preparation of the PRP. A highest concentration of leukocytes can lead to a higher concentration of PDGF (platelet growth factor $)^{11}$ and this is an important growth factor for tissue regeneration, since it is a potent stimulator of mesenchymal cells (fibroblasts, smooth muscle cells) mitogenesis ${ }^{24}$ in addition to stimulating angiogenesis and macrophage activation. ${ }^{15}$ The presence of leukocytes may increase the anti-microbial activity of PRP as well as analgesia. ${ }^{19}$

There is still much confusion regarding the classification of PRP. Dohan Ehrenfest et al. ${ }^{18}$ suggested the following classification: leukocyte poor PRP; platelet and leukocyte rich plasma; platelet rich and leukocyte poor fibrin; and platelet and leukocyte rich fibrin. We believe that PRP obtained by the method described in this study is the platelet and leukocyte rich plasma, as there was a large incremental factor for both, platelets and leukocytes.

\section{CONCLUSION}

The method described herein produces platelet and leukocyte rich plasma with high leukocyte and platelet incremental factor.

\section{ACKNOWLEDGEMENT}

Authors wish to thank Erik Fernandes for his support formatting the images, and are thankful to PCE Importação Comércio e Manutenção de Material Cirúrgico Ltda. for the support.

\section{REFERENCES}

1. Whitman $\mathrm{DH}$, Berry RL, Green DM. Platelet gel: an autologous alternative to fibrin glue with applications in oral and maxillofacial surgery. J Oral Maxillofac Surg. 1997;55(11):1294-9.

2. Matras $\mathrm{H}$. The use of fibrin sealant in oral and maxillofacial surgery. J Oral Maxillofac Surg. 1982;40(10):617-22.

3. Berghoff WJ, Pietrzak WS, Rhodes RD. Platelet-rich plasma application during closure following total knee arthroplasty. Orthopedics. 2006;29(7):590-8.

4. Creeper F, Lichanska AM, Marshall RI, Seymour GJ, Ivanovski S. The effect of platelet-rich plasma on osteoblast and periodontal ligament cell migration, proliferation and differentiation. J Periodontal Res. 2009;44(2):258-65.

5. Okuda K, Tai H, Tanabe K, Suzuki H, Sato T, Kawase T, et al. Platelet-rich plasma combined with a porous hydroxyapatite graft for the treatment of intrabony periodontal defects in humans: a comparative controlled clinical study. J Periodontol. 2005;76(6):890-8.

6. Ishida K, Kuroda R, Miwa M, Tabata Y, Hokugo A, Kawamoto T, et al. The regenerative effects of platelet-rich plasma on meniscal cells in vitro and its in vivo application with biodegradable gelatin hydrogel. Tissue Eng. 2007;13(5):1103-12.

7. Sanchez M, Azofra J, Anitua E, Andia I, Padilla S, Santisteban J, et al. Plasma rich in growth factors to treat an articular cartilage avulsion: a case report. Med Sci Sports Exerc. 2003;35(10):1648-52.

8. Freshwater MF. The use of platelet-rich plasma in plastic surgery remains unproven. J Plast Reconstr Aesthet Surg. 2013;66(3):311-2.

9. Griffin XL, Wallace D, Parsons N, Costa ML. Platelet rich therapies for long bone healing in adults. Cochrane Database Syst Rev. 2012;7:CD009496.

10. Martinez-Zapata MJ, Marti-Carvajal AJ, Sola I, Exposito JA, Bolibar I, Rodriguez L, et al. Autologous platelet-rich plasma for treating chronic wounds. Cochrane Database Syst Rev. 2012;10:CD006899.

11. Sommeling CE, Heyneman A, Hoeksema H, Verbelen J, Stillaert FB, Monstrey $\mathrm{S}$. The use of platelet-rich plasma in plastic surgery: a systematic review. J Plast Reconstr Aesthet Surg. 2013;66(3):301-11.

12. Eppley BL, Pietrzak WS, Blanton M. Platelet-rich plasma: a review of biology

and applications in plastic surgery. Plast Reconstr Surg. 2006;118(6):147e-59e. 13. Wojtys EM. The PRP Question. Sports Health. 2012;4(2):99-100.

14. Marx RE. Platelet-rich plasma (PRP): what is PRP and what is not PRP? Implant Dent. 2001:10(4):225-8.

15. Marx RE, Carlson ER, Eichstaedt RM, Schimmele SR, Strauss JE, Georgeff KR Platelet-rich plasma: Growth factor enhancement for bone grafts. Oral Surg Oral Med Oral Pathol Oral Radiol Endod. 1998;85(6):638-46.

16. Weibrich G, Kleis WK, Hafner G, Hitzler WE. Growth factor levels in platelet-rich plasma and correlations with donor age, sex, and platelet count. J Craniomaxillofac Surg. 2002;30(2):97-102.

17. Foster TE, Puskas BL, Mandelbaum BR, Gerhardt MB, Rodeo SA. Plateletrich plasma: from basic science to clinical applications. Am J Sports Med. 2009;37(11):2259-72.

18. Dohan Ehrenfest DM, Rasmusson L, Albrektsson T. Classification of platelet concentrates: from pure platelet-rich plasma (P-PRP) to leucocyte- and platelet-rich fibrin (L-PRF). Trends Biotechnol. 2009;27(3):158-67.

19. Arnoczky SP, Delos D, Rodeo SA. What is Platelet-Rich Plasma? Oper Tech Sports Med. 2011;19:142-8.

20. Alsousou J, Thompson M, Hulley P, Noble A, Willett K. The biology of plateletrich plasma and its application in trauma and orthopaedic surgery: a review of the literature. J Bone Joint Surg Br. 2009;91(8):987-96.

21. Castillo TN, Pouliot MA, Kim HJ, Dragoo JL. Comparison of growth factor and platelet concentration from commercial platelet-rich plasma separation systems. Am J Sports Med. 2011;39(2):266-71.

22. Floryan KM, Berghoff WJ. Intraoperative use of autologous platelet-rich and platelet-poor plasma for orthopedic surgery patients. AORN J. 2004;80(4):668-74

23. Listl S, Tu YK, Faggion CM Jr. A cost-effectiveness evaluation of enamel matrix derivatives alone or in conjunction with regenerative devices in the treatment of periodontal intra-osseous defects. J Clin Periodontol. 2010;37(10):920-7.

24. Deuel TF, Huang JS. Platelet-derived growth factor. Structure, function, and roles in normal and transformed cells. J Clin Invest. 1984;74(3):669-76. 